\title{
Prevalence of Orthostatic Hypertension in Elderly Patients with Type 2 Diabetes
}

\section{Patrícia Mesquita, Deborah Queiroz, Vanderson Lamartine de Lima Silva, Vanessa de Carvalho Texeira, Yasmin Rodrigues Vilaça de Lima, Edinaldo Rodrigues Fontes Júnior, Jéssica Garcia, and Francisco Bandeira}

\author{
Division of Endocrinology, Diabetes and Bone Diseases, Agamenon Magalhaes Hospital, \\ University of Pernambuco Medical School, Rua Raimundo Freixeiras 47, 52070-020 Recife, PE, Brazil
}

Correspondence should be addressed to Patrícia Mesquita; patymesq@hotmail.com

Received 24 July 2014; Revised 11 September 2014; Accepted 14 September 2014

Academic Editor: Nikolaos Papanas

\begin{abstract}
Copyright (C) 2015 Patrícia Mesquita et al. This is an open access article distributed under the Creative Commons Attribution License, which permits unrestricted use, distribution, and reproduction in any medium, provided the original work is properly cited.

Background. The aim of the present study was to determine the prevalence of orthostatic hypertension (OHT) in elderly patients with type 2 diabetes and its relation to metabolic and echocardiographic parameters. Methods. This was an analytical cross-sectional study in 97 patients normotensive or hypertensive. OHT was defined as a $\geq 10 \mathrm{mmHg}$ increase in systolic blood pressure after four minutes in the standing position. Results. The prevalence of OHT was $20.6 \%$. The mean body mass index was significantly higher in patients with OHT than in those without it $\left(29.80 \pm 4.10\right.$ versus $\left.27.51 \pm 3.98 \mathrm{~kg} / \mathrm{m}^{2} ; P=0.026\right)$. There were no statistically significant differences between the two groups for other metabolic parameters. Among the 68 patients who had an echocardiographic examination $27 \%$ of those with OHT had an increase in their left atrial volume index (LAVi) compared with $75 \%$ of those who did not have OHT $(P=0.004)$. The mean LAVi of patients with OHT was significantly lower than that of those without OHT $(26.27 \pm 6.37$ versus $32.65 \pm 7.54$, resp.; $P=0.011)$. Conclusion. We found a high prevalence of orthostatic hypertension and a lower left atrial volume indexed in the patients with orthostatic hypertension.
\end{abstract}

\section{Introduction}

Autonomic cardiac neuropathy is associated with significant morbidity and mortality in diabetics, the risk being greater in those with hypertension [1]. Some reports in the literature suggest that orthostatic hypertension occurs in some forms of autonomic dysfunction and in primary chronic conditions such as type 2 diabetes mellitus, elderly hypertensive individuals, and peripheral neuropathy [2].

The prevalence and clinical significance of orthostatic hypertension in diabetic patients are as yet not well understood, unlike postural hypotension, which is a common feature of advanced autonomic neuropathy in type 2 diabetes mellitus (T2DM) $[3,4]$.

The difficulty in determining the actual prevalence of orthostatic hypertension is due to several factors, such as the varying definitions used and differences between the populations that have been studied to date. There are studies that define orthostatic hypertension as a rise in systolic blood pressure (SBP) of $5 \mathrm{mmHg}$ [5], while others define it as an increase in SBP of $20 \mathrm{mmHg}$ [6]. Still others define it as an increase $>140 \mathrm{mmHg}$ in systolic and/or $90 \mathrm{mmHg}$ in diastolic blood pressure (DBP) after standing up [3].

In hypertensive patients, the prevalence and clinical significance of orthostatic hypertension also remain largely undetermined $[6,7]$. A recent study evaluated the association of orthostatic hypertension with cardiovascular disease (CVD) and damage to the target organ in 4,711 hypertensive and 826 normotensive patients. After controlling for confounders such as age and gender OHT was independently associated with peripheral arterial disease (OR 1.36, 95\% CI 1.05 to $1.81 ; P<0.05)$ and stroke (OR 1.76, 95\% CI 1.27 to 2.26; $P<0.01)[6]$.

In a study of 277 Japanese males with DM2, including 90 hypertensive patients and 128 nondiabetic males matched by age, excluding users of antihypertensive medications, 
the prevalence of orthostatic hypertension, in normotensive and hypertensive diabetics, was significantly higher than in the controls (12.8 versus $1.8 \% ; P<0.01$, for normotensive patients, and 12.6 versus $11.1 \%$, nonsignificant for hypertensive patients) [3]. A population-based study revealed a positive correlation of postural hypotension/hypertension and orthostatic dizziness in adults ( $\geq 20 \mathrm{yr})$ of all age groups, defining OHT as a postural increase in SBP $\geq 20 \mathrm{mmHg}$ and that age $(P<0.001)$ and systolic blood pressure in the supine position $(P=0.023)$ were correlated with orthostatic hypertension in a statistically significant manner, with the risk for this condition increasing in adults from the age of $40 \mathrm{yr}$ [8].

In view of the lack of published data on the prevalence of orthostatic hypertension in elderly patients with diabetes, this study was designed to determine the prevalence of orthostatic hypertension and its possible relation to metabolic factors and echocardiographic parameters in a population referred for treatment to an outpatient endocrine clinic.

\section{Subjects and Methods}

Approximately 4,800 patients spontaneously sought the outpatient endocrinology clinic at Agamenon Magalhães Hospital within six months of data collection. Assuming a $12 \%$ prevalence of orthostatic hypotension in normotensive and hypertensive diabetics, a sample of 375 patients with an error rate of $2.5 \%$ was calculated. However only 97 patients 60 years and older were evaluated, all of whom were diagnosed with type 2 diabetes mellitus. The patients were normotensive or hypertensive, receiving either angiotensin-converting enzyme inhibitors or angiotensin receptor blockers and/or a calcium channel blocker. The exclusion criteria were as follows: patients with type 1 diabetes mellitus; those reporting the chronic use of diuretics, beta blockers or alpha blockers for treatment of hypertension; heart failure patients with systolic ejection fraction $\leq 35 \%$, or functional class III or IV as established by the New York Heart Association; patients with atrial fibrillation; patients suffering from terminal chronic renal disease undergoing hemodialysis; patients with cancer at any site except the skin (nonmelanoma); those with rheumatic diseases (rheumatoid arthritis or arthrosis of the hands and feet); patients with limitations in the supine position; and those with Parkinson's disease or tremors of the extremities.

The patients answered a questionnaire after signing the informed consent form. The questionnaire consisted of age, sex, physical examination with measurement of weight, height, waist circumference, and hip circumference, physical exam-ination of the feet (tactile, thermal and vibratory sensitivity, presence or not of ulcer, and test monofilament), medications used, diagnosis of arterial hypertension, and time since diagnosis of diabetes mellitus. They were also evaluated for the presence of comorbidities, based on their previous diagnosis of cardiovascular disease due to acute myocardial infarction or coronary artery bypass graft (with bypass surgery or stenting) coronary angiography with stenosis of at least $\geq 50 \%$, ischemic stroke, $\geq 50 \%$ stenosis of the carotid, or previous peripheral arterial disease.

Patients underwent a thorough physical examination, including measurement of systolic blood pressure (SBP) and diastolic blood pressure (DBP) with an automatic device (Omron Health Care, Inc., Kyoto, Japan), weight, height, body mass index (BMI), waist circumference, and hip circumference.

Blood pressure was measured with the patient seated and again after four minutes in the standing position, using an automatic device (Omron Health Care, Inc., Kyoto, Japan). Two measurements were taken consecutively in seated and standing with the arm supported at heart level in both positions, the mean of the two being considered for purposes of assessment.

Blood samples were collected after 12 hours of fasting to determine serum levels of glucose, glycated hemoglobin, total cholesterol and fractions (LDL-cholesterol and HDLcholesterol), triglycerides, and creatinine.

Urine samples were collected for creatinine and protein determination.

Laboratory tests were performed using an autoanalyzer, Johnson \& Johnson, USA, and for HbA1C, Fugion, USA.

Patients underwent echocardiography (Philips Envisor USA, 2005), conducted by an examiner blinded to which patients had orthostatic hypertension. Measurements were made for left atrial volume and left ventricular mass.

\subsection{Definition of Concepts of Variables Studied}

(i) Orthostatic hypertension was defined as a $\geq 10 \mathrm{mmHg}$ increase in systolic blood pressure after 4 minutes in the standing position, compared with the sitting position.

(ii) According to the recommendations of the Committee of the American Society of Echocardiography (ASE) 2005 [9] the left atrial volume index (LAVi) was measured, which is the left atrial volume divided by the body surface area. Normal volumes were considered to be from 16 to $28 \mathrm{~mL} / \mathrm{m}^{2}$. LAVi greater than $28 \mathrm{~mL} / \mathrm{m}^{2}$ was considered to be altered. The left ventricle mass index (LVMi) was measured, which is the mass of the left ventricle divided by the body surface area. The normal female value was from 43 to $95 \mathrm{~g} / \mathrm{m}^{2}$, slightly abnormal between 96 and $108 \mathrm{~g} / \mathrm{m}^{2}$, moderately abnormal between 109 and $121 \mathrm{~g} / \mathrm{m}^{2}$, and critically abnormal $\geq 122 \mathrm{~g} / \mathrm{m}^{2}$. For male it ranged from 49 to $115 \mathrm{~g} / \mathrm{m}^{2}$, slightly abnormal between 116 and $131 \mathrm{~g} / \mathrm{m}^{2}$, moderately abnormal between 132 and $148 \mathrm{~g} / \mathrm{m}^{2}$, and critically abnormal $\geq 149 \mathrm{~g} / \mathrm{m}^{2}$.

The study was approved by the Agamenon Magalhães Hospital Ethics in Research Committee (registration CAAE.0114.0.236.000-11).

2.2. Statistical Analysis. In the statistical analysis the paired Student's $t$-test was used for numeric variables, Pearson's chi-square test for association of two categorical variables, or Fisher's exact test when it was not possible to use the chi-square test, and the Student's $t$-test demonstrated both equal and unequal variances. Verification of the hypothesis of equality of variances was performed using Levene's $F$-test 
and the correlation analysis using the $F$-test (ANOVA). Considering the confidence interval of $95 \%$, the index of significance was set at $P<0.05$. The software used was version 17 of the SPSS.

\section{Results}

Ninety-seven patients were studied with ages ranging from 60 to 88 years (median, $68.97 \mathrm{yr}, \mathrm{SD} \pm 6.80$ ), of whom $30.9 \%$ (30 patients) were males. The mean time since the diagnosis of diabetes was 12.23 years $( \pm 8.34$ years). Mean glycated hemoglobin was $7.9 \%( \pm 1.71 \%) .59(60.8 \%)$ patients were taking statins and 33 (34\%) patients used insulin. Of the 97 patients, 7 (7.2\%) had an ulcer on foot, 34 (24.7\%) had negative monofilament test, 35 (36.1\%) had a change (decreased or absent) in vibration sensitivity, 39 (40.2\%) had changes (decreased or absent) in thermal sensitivity, and 11 had changes (decreased or absent) of tactile sensitivity. The majority of patients in this study had hypertension $(77 ; 79.4 \%)$, were overweight or obese $(77 ; 79.3 \%)$, with a mean BMI of $27.95 \mathrm{~kg} / \mathrm{m}^{2}$ (Table 1). The prevalence of orthostatic hypertension was $20.6 \%$ (20 patients) (Table 1 ) with most patients being overweight or obese (BMI $\geq 25 \mathrm{~kg} / \mathrm{m}^{2}$ ) (19 patients, $52.5 \% ; P=0.111$ ) (Table 2 ). BMI was significantly higher in individuals with OHT than in those without $(29.80 \pm 4.10$ versus $\left.27.51 \pm 3.98 \mathrm{~kg} / \mathrm{m}^{2}, P=0.026\right)$. No statistically significant association was seen between orthostatic hypertension and abnormal physical examination of the feet. Of the orthostatic hypertension patients, $17(22.7 \%)$ had a diagnosis of systemic arterial hypertension $(P=0.551)$ (Table 2). Of the 68 patients who did an echocardiographic examination, bearing in mind that 29 patients did not have the examination, $27 \%$ (3 patients) from those with OHT had an increase in their left atrial volume index (iLAV) compared with $75 \%$ (43 patients) of those without OHT $(P=0.004)$. The mean iLAV of patients with OHT was significantly lower than those without it $(26.27 \pm 6.37$ versus $32.65 \pm 7.54$, resp., $P=0.011)$. We examined the interaction of BMI with the iLAV and found that the correlation persisted $(-0.092 ; P=0.452)$ (Table 3$)$.

\section{Discussion}

Available data shows a strong association between obesity and hypertension. In the Framingham study, the relative risk of hypertension in overweight men and women was 1.46 and 1.75 , respectively, after adjusting for age [10].

Data on OHT are not well characterized in the literature and its real clinical significance is unknown, although some studies carried out in recent years have suggested that orthostatic hypertension may be a new cardiovascular risk factor [11].

Orthostatic hypertension can vary from a simple incidental finding during a physical examination to a significant increase in blood pressure, resulting in baroreflex deregulation [2]. However its precise mechanism remains unclear [11].

Initial studies involving orthostatic hypertension showed that individuals with this condition had a greater decrease in cardiac output in the upright position, with an increase
TABLE 1: Clinical, laboratorial, and echocardiography characteristics of studied subjects.

\begin{tabular}{|c|c|}
\hline Variable & Mean \\
\hline Age (years) & $68.97 \pm 6.80$ \\
\hline \multicolumn{2}{|l|}{ Gender } \\
\hline Male & $30.9 \%$ \\
\hline Female & $69.1 \%$ \\
\hline Diabetes duration (years) & $12.23 \pm 8.34$ \\
\hline $\mathrm{BMI}\left(\mathrm{kg} / \mathrm{m}^{2}\right)$ & $27.95 \pm 4.06$ \\
\hline Waist circumference $(\mathrm{cm})$ & $98.45 \pm 12.43$ \\
\hline Hip circumference (cm) & $101.71 \pm 9.85$ \\
\hline Fasting glucose (mg/dL) & $143.20 \pm 56.41$ \\
\hline $\operatorname{HbA1C}(\%)$ & $7.90 \pm 1.71$ \\
\hline $\operatorname{MDRD}\left(\mathrm{mL} / \mathrm{min} / 1.73 \mathrm{~m}^{2}\right)$ & $91.85 \pm 25.98$ \\
\hline $\mathrm{HDL}(\mathrm{mg} / \mathrm{dL})$ & $52.91 \pm 22.73$ \\
\hline $\mathrm{LDL}(\mathrm{mg} / \mathrm{dL})$ & $97.95 \pm 31.95$ \\
\hline Triglycerides (mg/dL) & $136.61 \pm 58.75$ \\
\hline Medications & $\%$ \\
\hline Statin & 60.8 \\
\hline ACE inhibitor & 49.5 \\
\hline $\mathrm{ARB}$ & 23.7 \\
\hline CCB & 19.6 \\
\hline Aspirin & 52.6 \\
\hline Metformin & 76.3 \\
\hline Sulfonylurea & 32 \\
\hline Insulin & 34 \\
\hline \multicolumn{2}{|l|}{ Comorbidities } \\
\hline Hypertension & 79.4 \\
\hline Stroke & 4.1 \\
\hline Myocardial infarction & 3.1 \\
\hline $\mathrm{CABG}$ & 2.1 \\
\hline PVD & 1 \\
\hline Left atrial volume index $\left(\mathrm{mL} / \mathrm{m}^{2}\right)$ & $121.77 \pm 22.81$ \\
\hline Left ventricular mass index $\left(\mathrm{g} / \mathrm{m}^{2}\right)$ & $31.60 \pm 7.64$ \\
\hline $\begin{array}{l}\text { Orthostatic hypotension } \\
\text { (DSBP }>20 \text { and/or DDBP }>10 \mathrm{mmHg} \text { ) }\end{array}$ & $3.1 \%$ \\
\hline $\begin{array}{l}\text { Orthostatic hypertension } \\
\text { (DSBP } \geq 10 \mathrm{mmHg} \text { ) }\end{array}$ & $20.6 \%$ \\
\hline
\end{tabular}

ACE: angiotensin converting enzyme. ARB: angiotensin II receptor blockers. CCB: calcium channel blockers.

CABG: coronary artery bypass grafting.

PVD: peripheral vascular disease.

BMI: body mass index.

DSBP: differential systolic blood pressure.

DDBP: Differential diastolic blood pressure.

in venous blood flow in the lower extremities, and higher levels of plasma norepinephrine after standing up [12, 13]. The hypothesis was that the accumulation of venous blood leads to a reduction in cardiac output and that the response would be an increase in sympathetic activity, leading to elevated DBP. This hypothesis of venous pooling in the feet and subsequent decreased cardiac output initially seems paradoxical. Maybe in patients with orthostatic hypertension 
TABLE 2: Evaluation of the occurrence of orthostatic hypertension (OHT) according to clinical data.

\begin{tabular}{|c|c|c|c|c|c|c|}
\hline \multirow{2}{*}{ Variable } & \multicolumn{2}{|c|}{ Occurrence of OTH } & \multicolumn{2}{|c|}{ Total } & \multirow{2}{*}{$P$ value } & \multirow{2}{*}{$\mathrm{RP}(\mathrm{CI}$ of $95 \%)$} \\
\hline & $N$ & $\%$ & $N$ & $\%$ & & \\
\hline \multicolumn{7}{|l|}{ Diabetes duration (years) } \\
\hline$<10$ & 9 & 27.3 & 33 & 100.0 & \multirow{3}{*}{$P^{(1)}=0.677$} & $1.25(0.48$ to 3.26$)$ \\
\hline 10 to 19 & 5 & 17.9 & 28 & 100.0 & & $0.82(0.27$ to 2.49$)$ \\
\hline$>19$ & 5 & 21.7 & 23 & 100.0 & & 1.00 \\
\hline Group total & 19 & 22.6 & 84 & 100.0 & & \\
\hline \multicolumn{7}{|l|}{ BMI } \\
\hline Overweight & 8 & 29.6 & 27 & 100.0 & \multirow{3}{*}{$P^{(1)}=0.111$} & $* *$ \\
\hline Obese & 11 & 22.9 & 48 & 100.0 & & ** \\
\hline Normal & 1 & 5.0 & 20 & 100.0 & & $* *$ \\
\hline \multicolumn{7}{|l|}{$\mathrm{HBP}$} \\
\hline Yes & 17 & 22.7 & 75 & 100.0 & \multirow{2}{*}{$P^{(2)}=0.551$} & $1.51(0.49$ to 4.65$)$ \\
\hline No & 3 & 15.0 & 20 & 100.0 & & 1.00 \\
\hline \multicolumn{7}{|c|}{ Left atrial volume index $\left(\mathrm{mL} / \mathrm{m}^{2}\right)$} \\
\hline Abnormal & 3 & 6.5 & 46 & 100.0 & \multirow{2}{*}{$P^{(1)}=0.004^{*}$} & 1.00 \\
\hline Normal & 8 & 36.4 & 22 & 100.0 & & 5.58 (1.64 to 19.00$)$ \\
\hline \multicolumn{7}{|c|}{ Left ventricular mass index $\left(\mathrm{g} / \mathrm{m}^{2}\right)$} \\
\hline Severe & 4 & 16.0 & 25 & 100.0 & \multirow{4}{*}{$P^{(1)}=0.408$} & $* *$ \\
\hline Moderate & 3 & 20.0 & 15 & 100.0 & & $* *$ \\
\hline Slightly above normal & - & - & 11 & 100.0 & & $* *$ \\
\hline Normal & 4 & 23.5 & 17 & 100.0 & & ** \\
\hline Group total & 11 & 16.2 & 68 & 100.0 & & \\
\hline
\end{tabular}

*Significant association at the $5.0 \%$ level.

${ }^{*}$ Impossible to determine due to the occurrence of null and very low incidence rates.

(1) Using Fisher's exact test.

(2) Using Pearson's chi-square test.

BMI: body mass index.

HBP: high blood pressure.

TABLE 3: Statistics on left atrium volume according to BMI classification.

\begin{tabular}{lcccc}
\hline \multirow{2}{*}{ Statistics } & \multicolumn{3}{c}{ BMI classification } & \multirow{2}{*}{$P$ value } \\
& Normal & Overweight & Obese & \\
\hline (i) Mean & 34.84 & 30.06 & 31.62 & \\
(ii) Median & 32.74 & 30.17 & 30.76 & \\
(iii) Standard deviation & 8.85 & 6.01 & 8.62 & $P^{(1)}=0.118$ \\
(iv) Minimum value & 21.35 & 17.93 & 19.62 & \\
(v) Maximum value & 55.60 & 39.47 & 60.08 & \\
\hline${ }^{(1)}$ F-test (ANOVA). & & & &
\end{tabular}

the central sympathetic excitation is pathologically excessive. This process could take place in an environment of partial dysautonomia involving venous capacitance or in individuals with pathological deregulation in the brainstem or centers involved in autonomic control. Why some patients experience orthostatic hypotension while others demonstrate orthostatic hypertension in this situation remains unclear [2].

In the present study orthostatic hypertension was found to be present in $20.6 \%$ of the elderly diabetic patients. In the literature the prevalence of orthostatic hypertension varies greatly, depending on the definition used and the population studied. In a study of Japanese men with diabetes, the prevalence of orthostatic hypertension was $12.8 \%$ in normotensive patients and $12.6 \%$ in hypertensives ones, using an increase in SBP of the $20 \mathrm{mmHg}$ or more after 3 minutes in the supine position to define orthostatic hypertension [6]. In another study in young adults, orthostatic hypertension was defined as an increase of $5 \mathrm{mmHg}$ in SBP upon standing, and the prevalence of orthostatic hypertension was $16.2 \%$ [5]. Regarding type 2 diabetic patients, the prevalence of orthostatic hypertension, defined as blood pressure (BP) $<140 / 90 \mathrm{mmHg}$ in the supine position, and BP measured again after 1 minute standing of $140 / 90 \mathrm{mmHg}$ or more, the prevalence of HTO was 12.6\% [3].

In our study, with a population consisting of patients aged 60 years and more, we found no association between orthostatic hypertension and increase in age. However, there are some reports in the literature in which older people have a higher occurrence of orthostatic hypertension [8]. Likewise, others have found that a complication of orthostatic hypertension in diabetic patients may be associated with increased 
serum triglyceride concentrations [2]. Similar findings were not shown to be statistically significant in this study.

In a multivariate analysis, high BMI and not being treated with insulin were independent factor associated with OHT.

The literature consulted indicates an increased occurrence of orthostatic hypertension in elderly patients with hypertension [14]. However, in the present study on diabetic patients, no significant association was observed between orthostatic hypertension and high blood pressure.

Increased left atrial volume is often reported with age and with a variety of cardiovascular disorders [15], as in hypertensive patients [16]. In our study the occurrence of orthostatic hypertension and increases in left atrial volume index were not substantiated. Our finding of a lower iLAV in patients with OHT is due to unknown mechanism. One possibility is that our patients with OHT had a significant high BMI but had a lower iLAV, suggesting that OHT may not be a harmful phenomenon. They should therefore not be submitted to an intensive control of blood pressure, considering that the results of the ACCORD BP trial in diabetics [17] fail to show any reduction in the rate of major fatal or nonfatal cardiovascular events, even with an intensive control of their blood pressure.

A study on orthostatic changes in blood pressure and target organ damage showed no significant correlation between left ventricle mass index and the occurrence of orthostatic hypertension [14], no such association been observed, as in the present study.

Our study had three main limitations: the small size of the sample; the fact that 29 patients did not undergo echocardiography exam because it had to be done on a different day from the clinical examination of the patient; and the lack of a control group.

\section{Conclusion}

We found a high prevalence of orthostatic hypertension in elderly patients with type 2 diabetes. High BMI and not being treated with insulin were independent factors associated with OHT. A left atrial volume indexed was found significantly lower suggesting that OHT may not be a harmful phenomenon.

\section{Conflict of Interests}

The authors declare that there is no conflict of interests regarding the publication of this paper.

\section{Acknowledgments}

The authors wish to thank the members of the Division of Endocrinology, Diabetes and Bone Diseases, Agamenon Magalhães Hospital, University of Pernambuco Medical School, Recife, Brazil, for their much appreciated support.

\section{References}

[1] I. Istenes, K. Keresztes, Z. Hermányi et al., “Relationship between autonomic neuropathy and hypertension-are we underestimating the problem?" Diabetic Medicine, vol. 25, no. 7, pp. 863-866, 2008.

[2] D. Robertson, "Orthostatic hypertension: the last hemodynamic frontier," Hypertension, vol. 57, no. 2, pp. 158-159, 2011.

[3] M. Yoshinari, M. Wakisaka, U. Nakamura, M. Yoshioka, Y. Uchizono, and M. Iwase, "Orthostatic hypertension in patients with type 2 diabetes," Diabetes Care, vol. 24, no. 10, pp. 1783$1786,2001$.

[4] E. A. Jarmuzewska, R. Rocchi, and A. A. Mangoni, "Predictors of impaired blood pressure homeostasis during acute and sustained orthostasis in patients with type 2 diabetes," Panminerva Medica, vol. 48, no. 1, pp. 67-72, 2006.

[5] R. J. Thomas, K. Liu, D. R. Jacobs Jr., D. E. Bild, C. I. Kiefe, and S. B. Hulley, "Positional change in blood pressure and 8-year risk of hypertension: the CARDIA study," Mayo Clinic Proceedings, vol. 78, no. 8, pp. 951-958, 2003.

[6] X.-H. Fan, Y. Wang, K. Sun et al., "Disorders of orthostatic blood pressure response are associated with cardiovascular disease and target organ damage in hypertensive patients," American Journal of Hypertension, vol. 23, no. 8, pp. 829-837, 2010.

[7] S. Vardan, N. E. Hill, K. G. Mehrotra, S. Mookherjee, and H. Smulyan, "Hormonal response to orthostasis in elderly people with systemic systolic hypertension," Coronary Artery Disease, vol. 9, no. 9, pp. 597-601, 1998.

[8] J.-S. Wu, Y.-C. Yang, F.-H. Lu, C.-H. Wu, and C.-J. Chang, "Population-based study on the prevalence and correlates of orthostatic hypotension/hypertension and orthostatic dizziness," Hypertension Research, vol. 31, no. 5, pp. 897-904, 2008.

[9] R. M. Lang, M. Bierig, R. B. Devereux et al., "Recommendations for chamber quantification: a report from the American Society of Echocardiography's guidelines and standards committee and the Chamber Quantification Writing Group, developed in conjunction with the European Association of Echocardiography, a branch of the European Society of Cardiology," Journal of the American Society of Echocardiography, vol. 18, no. 12, pp. 14401463, 2005.

[10] P. W. Wilson, R. B. D’Agostino, L. Sullivan, H. Parise, and W. B. Kannel, "Overweight and obesity as determinants of cardiovascular risk; the Framingham experience," Archives of Internal Medicine, vol. 162, pp. 1867-1872, 2002.

[11] K. Kario, "Orthostatic hypertension-a measure of blood pressure variation for predicting cardiovascular risk," Circulation Journal, vol. 73, no. 6, pp. 1002-1007, 2009.

[12] D. H. P. Streeten, J. H. Auchincloss Jr., G. H. Anderson Jr., R. L. Richardson, F. D. Thomas, and J. W. Miller, "Orthostatic hypertension: pathogenetic studies," Hypertension, vol. 7, no. 2, pp. 196-203, 1985.

[13] D. H. P. Streeten, G. H. Anderson Jr., R. Richardson, and F. D. Thomas, "Abnormal orthostatic changes in blood pressure and heart rate in subjects with intact sympathetic nervous function: evidence for excessive venous pooling," Journal of Laboratory and Clinical Medicine, vol. 111, no. 3, pp. 326-335, 1988.

[14] K. Eguchi, K. Kario, S. Hoshide et al., "Greater change of orthostatic blood pressure is related to silent cerebral infarct and cardiac overload in hypertensive subjects," Hypertension Research, vol. 27, no. 4, pp. 235-241, 2004.

[15] G. P. Aurigemma, J. S. Gottdiener, A. M. Arnold, M. Chinali, J. C. Hill, and D. Kitzman, "Left atrial volume and geometry in 
healthy aging the cardiovascular health study," Circulation: Cardiovascular Imaging, vol. 2, no. 4, pp. 282-289, 2009.

[16] S. Eshoo, D. L. Ross, and L. Thomas, "Impact of mild hypertension on left atrial size and function," Circulation: Cardiovascular Imaging, vol. 2, no. 2, pp. 93-99, 2009.

[17] ACCORD Study Group, "Effects of intensive blood-pressure control in type 2 diabetes mellitus," The New England Journal of Medicine, vol. 362, no. 17, pp. 1575-1585, 2010. 


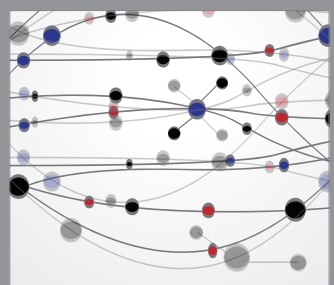

The Scientific World Journal
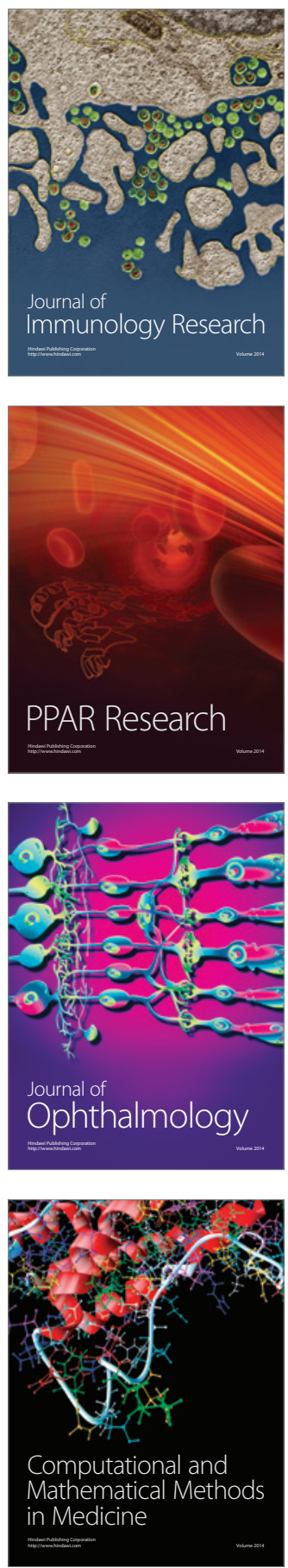

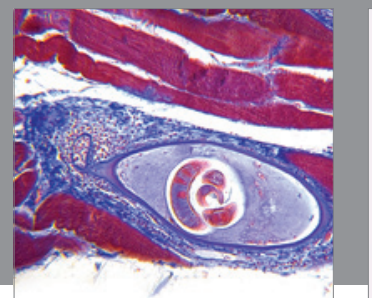

Gastroenterology

Research and Practice
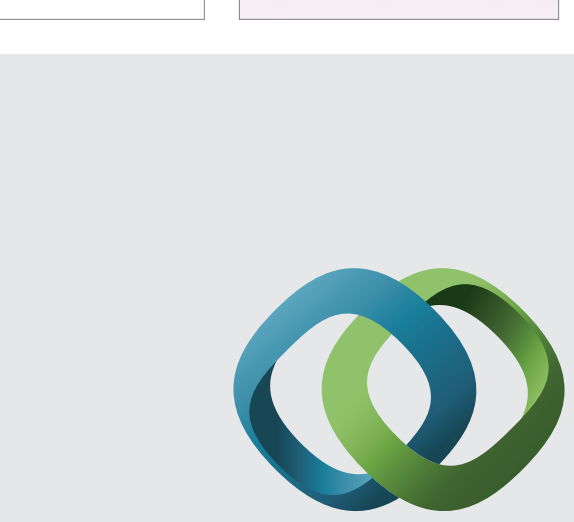

\section{Hindawi}

Submit your manuscripts at

http://www.hindawi.com
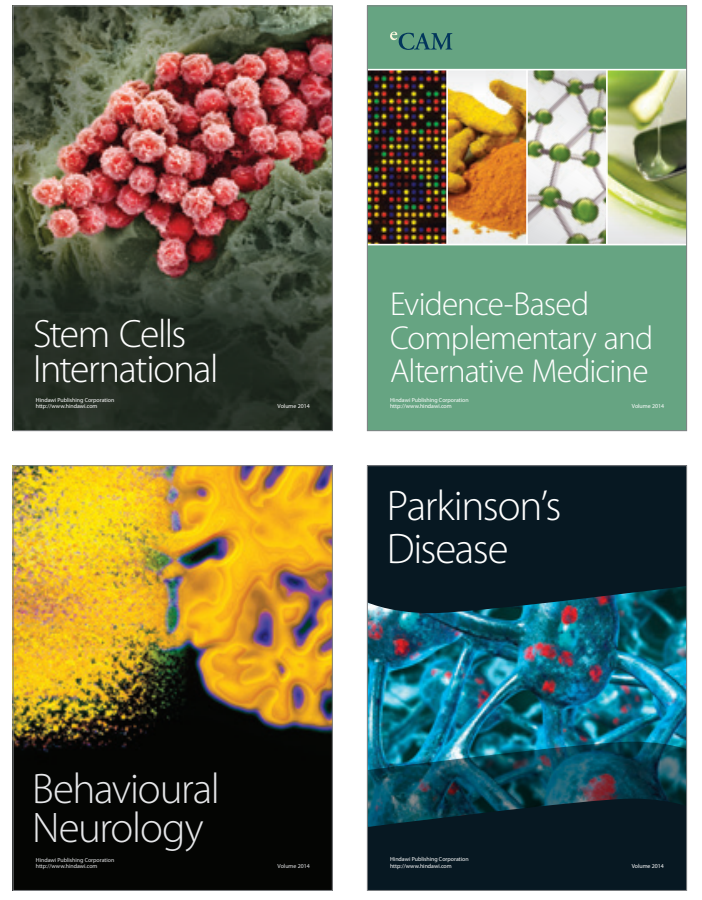
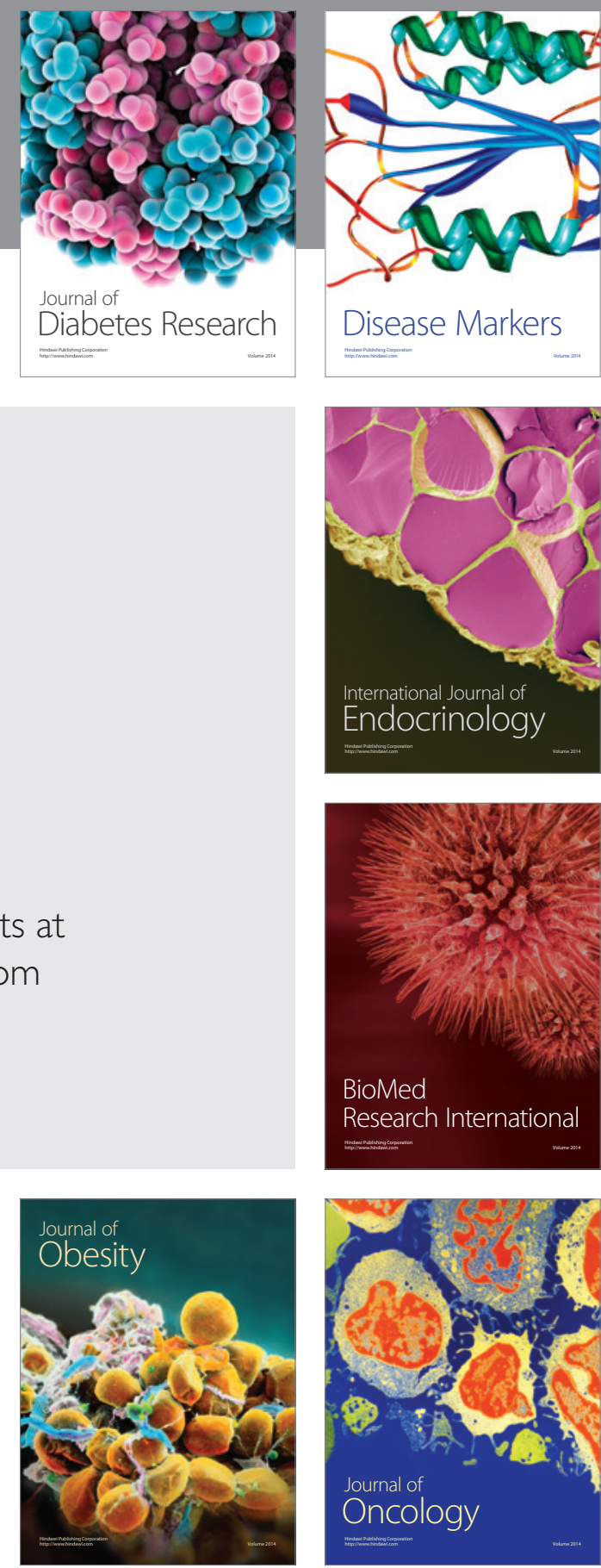

Disease Markers
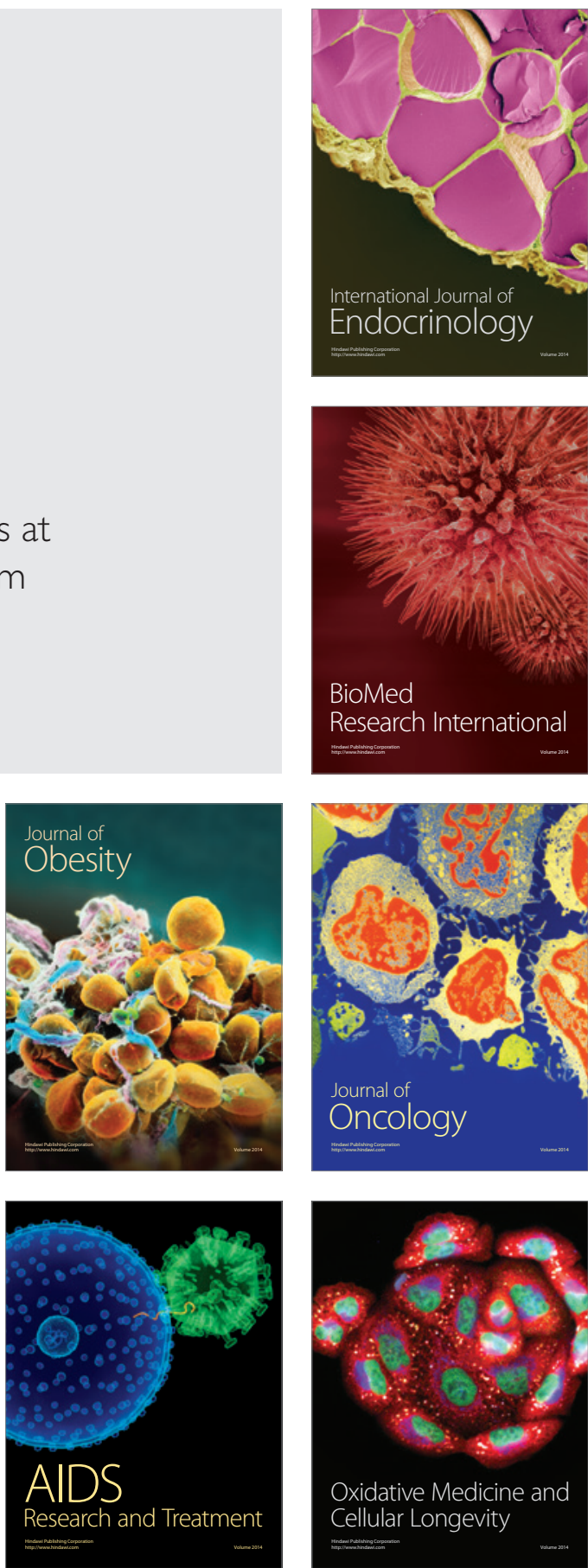